Supplement of Biogeosciences, 14, 1493-1509, 2017

http://www.biogeosciences.net/14/1493/2017/

doi:10.5194/bg-14-1493-2017-supplement

(C) Author(s) 2017. CC Attribution 3.0 License.

(c) (i)

Supplement of

\title{
Physiology regulates the relationship between coccosphere geometry and growth phase in coccolithophores
}

Rosie M. Sheward et al.

Correspondence to: Rosie M. Sheward (sheward@em.uni-frankfurt.de)

The copyright of individual parts of the supplement might differ from the CC-BY 3.0 licence. 
Table S1. Growth phase experiment days (D), mean exponential growth rates $(\mu)$ and summary statistics for species-specific coccosphere geometry data for exponential-phase days of growth (Exp) and non-exponential-phase days of growth (Non-exp). Minimum, mean and maximum PIC (particulate inorganic carbon) calculated for selected exponential- and non-exponential-phase days from the $22{ }^{\circ} \mathrm{C}$ experiment are shown, which were used for the calculations reported in Sect. 4.4 and displayed in Fig. 5. The full dataset of experimental conditions, daily growth rates and coccosphere geometry measurements from each individual coccosphere is available as Sheward et al. (2016) at https://doi.pangaea.de/doi:10.1594/PANGAEA.865403.

\begin{tabular}{|c|c|c|c|c|c|c|c|c|c|}
\hline \multirow[t]{2}{*}{ Parameter } & & \multicolumn{2}{|c|}{ Helicosphaera carteri } & \multicolumn{2}{|c|}{ Calcidiscus leptoporus } & \multicolumn{2}{|c|}{$\begin{array}{l}\text { Calcidiscus } \\
\text { quadriperforatus }\end{array}$} & \multicolumn{2}{|c|}{ Coccolithus braarudii } \\
\hline & & Exp & Non-exp & Exp & Non-exp & Exp & Non-exp & Exp & Non-exp \\
\hline $\begin{array}{l}\text { Number of } \\
\text { values }\end{array}$ & & 780 & 210 & 870 & 150 & 690 & 150 & 250 & 50 \\
\hline $\begin{array}{l}\text { Experiment } \\
\text { days, D }\end{array}$ & $\begin{array}{l}22^{\circ} \mathrm{C} \\
20^{\circ} \mathrm{C} \\
18^{\circ} \mathrm{C} \\
16^{\circ} \mathrm{C} \\
15^{\circ} \mathrm{C}\end{array}$ & $\begin{array}{l}\leq \mathrm{D} 11 \\
\leq \mathrm{D} 7 \\
\leq \mathrm{D} 15 \\
\leq \mathrm{D} 13 \\
-\end{array}$ & $\begin{array}{l}\text { D12-14 } \\
\text { D8 } \\
\text { D16-17 } \\
\text { D14-17 } \\
-\end{array}$ & $\begin{array}{l}\leq \mathrm{D} 15 \\
\leq \mathrm{D} 11 \\
\leq \mathrm{D} 17 \\
\leq \mathrm{D} 18 \\
-\end{array}$ & $\begin{array}{l}\text { D16-23 } \\
\text { D12-13 } \\
\text { D18-19 } \\
- \\
-\end{array}$ & $\begin{array}{l}\leq \mathrm{D} 11 \\
\leq \mathrm{D} 11 \\
\leq \mathrm{D} 15 \\
\leq \mathrm{D} 16 \\
-\end{array}$ & $\begin{array}{l}\text { D12-15 } \\
\text { D12-13 } \\
\text { D16-17 } \\
\text { D17-18 } \\
-\end{array}$ & $\begin{array}{l}- \\
- \\
- \\
- \\
\leq \mathrm{D} 10\end{array}$ & $\begin{array}{l}- \\
- \\
- \\
- \\
\text { D11-15 }\end{array}$ \\
\hline $\begin{array}{l}\text { Mean growth } \\
\text { rates, } \mu \\
d^{-1}\end{array}$ & $\begin{array}{l}22^{\circ} \mathrm{C} \\
20^{\circ} \mathrm{C} \\
18^{\circ} \mathrm{C} \\
16^{\circ} \mathrm{C} \\
15^{\circ} \mathrm{C}\end{array}$ & $\begin{array}{l}0.35 \\
0.45 \\
0.28 \\
0.28 \\
-\end{array}$ & $\begin{array}{l}- \\
- \\
- \\
-\end{array}$ & $\begin{array}{l}0.34 \\
0.44 \\
0.32 \\
0.36 \\
-\end{array}$ & $\begin{array}{l}- \\
- \\
- \\
-\end{array}$ & $\begin{array}{l}0.44 \\
0.43 \\
0.33 \\
0.30 \\
-\end{array}$ & $\begin{array}{l}- \\
- \\
- \\
-\end{array}$ & $\begin{array}{l}- \\
- \\
- \\
- \\
0.68\end{array}$ & $\begin{array}{l}- \\
- \\
- \\
- \\
-\end{array}$ \\
\hline $\begin{array}{l}\text { Coccosphere } \\
\text { diameter, } \\
\mu \mathrm{m}\end{array}$ & $\begin{array}{l}\text { Min } \\
\text { Mean } \\
\text { Max }\end{array}$ & $\begin{array}{l}9.35 \\
14.88 \\
20.90\end{array}$ & $\begin{array}{l}11.64 \\
15.52 \\
19.50\end{array}$ & $\begin{array}{l}10.02 \\
13.15 \\
19.72\end{array}$ & $\begin{array}{l}10.79 \\
14.02 \\
17.28\end{array}$ & $\begin{array}{l}13.84 \\
18.44 \\
24.39\end{array}$ & $\begin{array}{l}15.28 \\
19.09 \\
22.99\end{array}$ & $\begin{array}{l}15.18 \\
20.80 \\
29.14\end{array}$ & $\begin{array}{l}16.13 \\
22.14 \\
29.42\end{array}$ \\
\hline $\begin{array}{l}\text { Cell diameter, } \\
\Theta \\
\mu \mathrm{m}\end{array}$ & $\begin{array}{l}\text { Min } \\
\text { Mean } \\
\text { Max }\end{array}$ & $\begin{array}{l}6.53 \\
10.18 \\
17.99\end{array}$ & $\begin{array}{l}9.26 \\
10.56 \\
16.68\end{array}$ & $\begin{array}{l}6.39 \\
9.78 \\
16.54\end{array}$ & $\begin{array}{l}7.09 \\
10.44 \\
13.96\end{array}$ & $\begin{array}{l}8.64 \\
13.54 \\
18.81\end{array}$ & $\begin{array}{l}10.42 \\
14.55 \\
18.77\end{array}$ & $\begin{array}{l}11.24 \\
16.51 \\
24.10\end{array}$ & $\begin{array}{l}12.48 \\
17.99 \\
22.44\end{array}$ \\
\hline $\begin{array}{l}\text { Coccolith } \\
\text { length, } C_{L} \\
\mu \mathrm{m}\end{array}$ & $\begin{array}{l}\text { Min } \\
\text { Mean } \\
\text { Max }\end{array}$ & $\begin{array}{l}6.70 \\
8.05 \\
11.22\end{array}$ & $\begin{array}{l}7.05 \\
8.17 \\
10.89\end{array}$ & $\begin{array}{l}5.02 \\
6.70 \\
8.76\end{array}$ & $\begin{array}{l}5.39 \\
6.80 \\
8.61\end{array}$ & $\begin{array}{l}5.67 \\
9.08 \\
11.67\end{array}$ & $\begin{array}{l}7.40 \\
9.18 \\
10.87\end{array}$ & $\begin{array}{l}8.13 \\
11.73 \\
15.33\end{array}$ & $\begin{array}{l}7.92 \\
11.43 \\
13.84\end{array}$ \\
\hline $\begin{array}{l}\text { Coccoliths per } \\
\text { cell, } C_{N} \\
\mu \mathrm{m}\end{array}$ & $\begin{array}{l}\text { Min } \\
\text { Mean } \\
\text { Max }\end{array}$ & $\begin{array}{l}6 \\
15 \\
30\end{array}$ & $\begin{array}{l}8 \\
17 \\
25\end{array}$ & $\begin{array}{l}10 \\
19 \\
45\end{array}$ & $\begin{array}{l}11 \\
21 \\
35\end{array}$ & $\begin{array}{l}8 \\
18 \\
29\end{array}$ & $\begin{array}{l}12 \\
20 \\
28\end{array}$ & $\begin{array}{l}5 \\
10 \\
20\end{array}$ & $\begin{array}{l}8 \\
13 \\
20\end{array}$ \\
\hline $\begin{array}{l}22^{\circ} \mathrm{C} \\
\text { experiment } \\
\text { days incl. }\end{array}$ & & D6, 7, 8 & D11-14 & $\mathrm{D} 7,9,11$ & $\begin{array}{l}\text { D19, 20, } \\
21\end{array}$ & D3, 5,7 & $\mathrm{D} 13,15$ & $\leq \mathrm{D} 11$ & D12-15 \\
\hline $\begin{array}{l}\text { PIC } \\
\text { pmol C cell }{ }^{-1}\end{array}$ & $\begin{array}{l}\text { Min } \\
\text { Mean } \\
\text { Max }\end{array}$ & $\begin{array}{l}7.79 \\
25.79 \\
49.38\end{array}$ & $\begin{array}{l}13.44 \\
28.68 \\
50.52\end{array}$ & $\begin{array}{l}3.27 \\
10.91 \\
25.34\end{array}$ & $\begin{array}{l}4.06 \\
15.76 \\
29.54\end{array}$ & $\begin{array}{l}15.06 \\
29.31 \\
57.88\end{array}$ & $\begin{array}{l}17.16 \\
31.91 \\
54.34\end{array}$ & $\begin{array}{l}6.97 \\
27.90 \\
70.09\end{array}$ & $\begin{array}{l}7.25 \\
33.80 \\
85.82\end{array}$ \\
\hline Reference & & This study & & This study & & This study & & $\begin{array}{l}\text { Gibbs } \\
(2013) \\
\text { Shewa } \\
\text { al. (20 }\end{array}$ & \\
\hline
\end{tabular}

